\title{
The effect of ulipristal acetate on tumor necrosis factor alpha, insulin-like growth factor 1 , and plasminogen activator inhibitor-1 serum levels in patients with symptomatic uterine fibroids
}

\author{
Michał Ciebiera ${ }^{1}$, Grzegorz Jakiel², Grażyna Nowicka³ , Antonio Simone Laganà ${ }^{4}$, Fabio Ghezzi ${ }^{4}$, \\ Tomasz Łoziński ${ }^{5}$, Cezary Wojtyła ${ }^{6,7}$, Marta Włodarczyk ${ }^{3}$
}

\author{
${ }^{1}$ Il Department of Obstetrics and Gynecology, The Center of Postgraduate Medical \\ Education, Warsaw, Poland \\ 2I Department of Obstetrics and Gynecology, The Center of Postgraduate Medical \\ Education, Warsaw, Poland \\ ${ }^{3}$ Department of Biochemistry and Pharmacogenomics, Faculty of Pharmacy, \\ Medical University of Warsaw, Poland \\ 4Department of Obstetrics and Gynecology, "Filippo Del Ponte" Hospital, \\ University of Insubria, Varese, Italy \\ ${ }^{5}$ Pro-Familia Hospital, Rzeszów, Poland \\ ${ }^{6}$ European Observatory of Health Inequalities, State University of Applied Sciences, \\ Kalisz, Poland \\ ${ }^{7}$ Department of Gynecologic Oncology and Obstetrics, The Center of Postgraduate \\ Medical Education, Warsaw, Poland
}

Submitted: 7 July 2019

Accepted: 2 January 2020

Arch Med Sci

DOI: https://doi.org/10.5114/aoms.2020.94296

Copyright (c) 2020 Termedia \& Banach

\begin{abstract}
Introduction: Uterine fibroids (UFs) are benign tumors of the female reproductive system originating from the smooth muscle of the uterus. Currently, progesterone is known to play a key role in the differentiation of the myometrial tissue to form UFs and their abnormal growth. The mechanism of action of progesterone in UF tumorigenesis involves its effect on increasing the concentrations and dysregulation of selected growth factors.

Material and methods: A retrospective cohort study was performed to evaluate and compare tumor necrosis factor alpha (TNF- $\alpha$ ), insulin-like growth factor 1 (IGF-1), plasminogen activator inhibitor-1 (PAI-1) serum concentrations in patients with UFs without prior hormonal treatment, patients with UFs treated with a 3-month standard ulipristal acetate (UPA - a type of selective progesterone receptor modulator) scheme $(5 \mathrm{mg} /$ day) and in control patients without UFs. A total of 120 patients were divided into 3 groups (controls, UFs with UPA treatment, UFs without UPA treatment).

Results: There were no significant differences in TNF- $\alpha$ serum concentrations between patients with UFs who underwent UPA treatment and patients who did not. Serum concentrations of IGF-1 and PAI-1 did not show significant intergroup differences.

Conclusions: No significant differences were found between TNF- $\alpha$ concentrations in the serum of patients with UFs treated with UPA, and patients without UPA treatment. In addition, our data analysis did not show significant differences in the concentrations of IGF-1 and PAI-1 between patients with UFs and the control group. Further studies on the dependence of specific symptoms on selected growth factors are mandatory.
\end{abstract}

Key words: uterine fibroid, selective progesterone receptor modulator, ulipristal acetate, tumor necrosis factor alpha, insulin-like growth factor, plasminogen activator inhibitor.

\author{
Corresponding author: \\ Michat Ciebiera \\ II Department of Obstetrics \\ and Gynecology \\ The Center of Postgraduate \\ Medical Education \\ 80 Cegłowska St \\ 01-809 Warsaw, Poland \\ E-mail: \\ michal.ciebiera@gmail.com
}




\section{Introduction}

Uterine fibroids (UFs) are benign tumors of the female reproductive system originating from the smooth muscle of the uterus [1]. These tumors are a particularly common pathology of the reproductive system and may affect up to $70 \%$ of women $[2,3]$. They are usually asymptomatic, but they may cause a broad spectrum of signs and symptoms, depending on the number, size and location [4]. The manifestations may impair the quality of life (QoL) $[5,6]$. The most common ones include anemia, pain and compression of pelvic and abdominal organs, gastrointestinal symptoms, urinary system disorders [2-4], infertility [7] and adverse obstetric outcomes $[8,9]$. The uterine fibroids classification by the International Federation of Gynecology and Obstetrics (FIGO) lists the main types of these tumors according to their location. In general, UFs may be divided into intracavitary, submucosal, intramural, subserosal and pedunculated ones $[10,11]$. Both indirect and direct costs associated with the diagnostic work-up and treatment of UFs constitute a heavy economic burden for health care budgets worldwide [12].

Despite many years of intensive research, the pathophysiology of UFs has been poorly elucidated and numerous issues still need to be analyzed [1, 13, 14]. Accumulating evidence suggests that some intrinsic abnormalities of the myometrium, abnormal myometrial receptors for estrogen, and hormonal changes or altered responses to ischemic damage during menstruation may be responsible for the initiation of genetic and epigenetic changes found in the myometrium and UFs $[1,15]$. The main factors determining UF development and growth include steroid hormones, genetic predisposition and the influence of growth factors $[13,16,17]$. According to the literature UFs are caused by monoclonal proliferation of an immortalized myometrial cell, which escapes from cell cycle control [18]. Tumor growth occurs through numerous cell divisions, as well as the production and accumulation of an increased amount of extracellular matrix (ECM) [19], depending on hormonal stimulation $[1,13,14]$.

To date, progesterone has been considered one of the main factors initiating the differentiation of the myometrial tissue into UF and its subsequent abnormal growth [16, 17]. In particular, its mechanism of action in UF tumorigenesis involves the effect on increasing the concentrations and the dysregulation of selected growth factors $[13,14,20]$. These factors are secreted within the UF microenvironment, resulting in self-stimulating neoplastic proliferation due to altered levels of transforming growth factors, vascular growth factors, platelet-derived growth factor and others [20-24].
Tumor necrosis factor alpha (TNF- $\alpha$ ) is one of the main cytokines responsible for the reactions of the acute phase. It is mostly produced by activated macrophages [25]. The dysregulation of the production and distribution of TNF- $\alpha$ was demonstrated to be of key importance in the pathophysiology of various diseases, including injuries and neoplasms [23, 26-28]. Increased expression of TNF- $\alpha$ was found in the tissues of UFs compared to the normal myometrium surrounding them [24]. In addition, TNF- $\alpha$ secreted by adipocytes was found to increase the proliferation of UF cells [29]. Available data suggest the occurrence of TNF- $\alpha$-induced inflammation in patients with UFs [30-32]. Finally, numerous symptoms associated with UFs may be recognized as dependent on elevated TNF- $\alpha$ concentrations in women affected by these tumors [20, 23, 33].

Insulin-like growth factor (IGF) was shown to play an important role in the promotion of cell proliferation and inhibition of cell death [34]. According to the literature IGF-1 and IGF-2 are present in UFs and healthy myometrial tissue [35]. Accumulating evidence suggests that IGF-1 plays a crucial role in UF tumor growth by increasing the expression of proliferating cell nuclear antigen (PCNA) and up-regulation of the apoptosis pathway protein $\mathrm{Bcl}-2$ [20]. On the one hand, higher levels of IGF-1 were found in large UFs in comparison with small ones, suggesting that IGF-1 dysregulation may be (at least partially) due to the in fluence of various mechanisms that stimulate UF tumor growth [20, 36, 37]. However, other authors reported that progesterone plays an important role in the differential expression of growth factor receptors in UFs, such as IGF receptor I [38].

Increased levels of plasminogen activator inhibitor-1 (PAI-1) were found in several diseases. PAI-1 is able to suppress fibrinolysis and is involved in the regulation of cell replication and angiogenesis [39-41]. Interestingly, changes in PAI-1 expression lead to altered growth factor activity in the ECM [42] In addition, Rutanen et al. [43] suggested a relationship between continuous induction of PAI-1 and improved efficiency in menorrhagia therapy.

Selective progesterone receptor modulators (SPRMs) have been used in the treatment of UFs for several years $[44,45]$. These drugs may act as agonists or full antagonists for the progesterone receptor. Therefore, they may provoke different clinical effects [46]. The use of SPRMs causes a measurable reduction in tumor size and related symptoms in women with UFs [44, 47-50]. Clinical trials on one of the SPRMs, i.e. ulipristal acetate (UPA), showed that this drug is effective in the case of abnormal excessive bleeding caused by UFs and in the reduction of UF volume [ 45 , 47-49, 51]. In particular, patients receiving UPA 
reported a considerable reduction in symptoms associated with UFs, and an overall improvement of their QoL [51]. Therefore, UPA treatment may be considered before the surgical removal of UFs [44, 45, 52]. Some reports were published concerning the pathways of action of UPA in UFs (such as the influence on metalloproteinases and growth factors) [53-55]. According to the most recent publications UPA was found to inhibit endogenous glucocorticoid signaling in human liver and UF tumor cells [56], which is also connected with the paragraph above, as IGF-1 plays an important role in modulating the metabolism of glucocorticoids [57]. However, not all of the proposed mechanisms have been clarified and confirmed so far. In addition, UPA was found to increase the risk of liver dysfunction in cases of previous (known or unknown) baseline alterations. Therefore, a safety alert has recently been published, requiring liver function to be checked before, during and after treatment [58]. Nevertheless, other authors suggested that this recommendation could be considered an overstatement, due to the low rate of adverse events regarding liver dysfunction in the general population of UPA users [59, 60].

The aim of the present study was to investigate serum levels of TNF- $\alpha$, IGF-1 and PAI- 1 in patients with UFs without treatment and patients treated with a 3-month standard UPA scheme ( $5 \mathrm{mg} /$ day).

\section{Material and methods}

\section{Patients}

The analysis was performed between September 2014 and May 2015, at the First Department of Obstetrics and Gynecology, The Center of Postgraduate Medical Education, Warsaw, Poland. The design, analysis, interpretation of data, drafting and revisions conform to the Helsinki Declaration and the STROBE (strengthening the reporting of observational studies in epidemiology) statement, available through the EQUATOR (enhancing the quality and transparency of health research) network (www.equator-network.org). The study was approved by the independent Institutional Review Board of the The Center of Postgraduate Medical Education, Warsaw, Poland. Each patient enrolled in this study signed informed consent for all the procedures and to allow data collection and analysis for research purposes. The study was not advertised, and no remuneration was offered to encourage patients to give consent for the collection and analysis of their data. Patients enrolled in this study were also a part of previous studies on transforming growth factor beta (TGF- $\beta 3$ ) and UPA treatment and TNF- $\alpha$, published earlier by our team $[32,55]$.

A total of 120 Caucasian women were included in this study. They were divided into three groups: women without UFs (controls, $n=49$ ); patients with UFs without prior UPA treatment (non-UPA group, $n=61$ ); patients with UFs after a 3-month preoperative UPA treatment (oral $5 \mathrm{mg} /$ day) (UPA group, $n=10)$.

The control group consisted of women without previously identified UFs who were recruited from the outpatient clinic during their gynecological visits. This group included premenopausal women who were at least 18 years of age without UFs on an transabdominal or transvaginal ultrasound scan. The demographic characteristics of the study groups are included in Table I.

The inclusion criteria for patients without prior UPA treatment were: age equal to or more than 18 years, at least one UF (minimum of $10 \mathrm{~mm}$ in diameter) found on transvaginal or transabdominal ultrasound examination, and eligibility for the surgical removal of the UF due to clinical symptoms (e.g. abnormal or excessive uterine bleeding, iron deficiency anemia, abdominal and pelvic pain or pressure, adjacent organ disorders, and female infertility).

The exclusion criteria for all groups were: additional hormonal therapy during the previous 6 months, menopause, pregnancy, any previous or current diabetes, hyperprolactinemia or neoplastic disease.

\section{Methods}

Ultrasound scans were performed by a certified gynecologist in two-dimensional gray-scale presentation transvaginally and/or transabdominally (if necessary). A UF was defined as a hypoechogenic and heterogenous area with detectable distinct margins. Uterine fibroid sizes varied from approximately $2 \mathrm{~cm}$ to the maximum of about $9 \mathrm{~cm}$ in diameter.

Venous fasting blood samples were collected from the patients. In UF-positive patients, in both non-UPA and UPA groups, the blood samples were taken a day before the surgery. The serum was separated immediately, and aliquots were frozen at $-80^{\circ} \mathrm{C}$ until needed for biochemical analyses. The enzyme-linked immunosorbent assay (ELISA) method was used to determine serum levels of TNF- $\alpha$ (Invitrogen, USA), IGF-I (Mediagnost, Germany) and PAI-1 (Invitrogen, USA). Each sample was measured in duplicate with an Epoch microplate analyzer (BioTek), according to the manufacturer's protocols. The minimum detectable dose was $0.09 \mathrm{pg} / \mathrm{ml}$ for TNF- $\alpha, 0.091 \mathrm{ng} / \mathrm{ml}$ for IGF-1, and $30 \mathrm{ng} / \mathrm{ml}$ for PAI- 1 . The intraassay coefficient of variation (CV\%) was 5.5 for TNF- $\alpha$, 5.8 for IGF-1, and 5.6 for PAI-1.

\section{Statistical analysis}

Values were expressed as means, medians, standard deviation (SD) and standard error of the mean (SE). Data were analyzed with the Kruskal-Wallis 
Table I. Characteristics of the study population

\begin{tabular}{|lccccc|}
\hline Parameter & $\begin{array}{c}\text { All subjects } \\
(N=120)\end{array}$ & $\begin{array}{c}\text { Controls } \\
(n=49)\end{array}$ & $\begin{array}{c}\text { Non-UPA } \\
(n=61)\end{array}$ & $\begin{array}{c}\text { After UPA } \\
(n=10)\end{array}$ & $\begin{array}{c}\boldsymbol{P} \\
\text { Age }[\text { years] }\end{array}$ \\
\hline BMI $\left[\mathrm{kg} / \mathrm{m}^{2}\right]$ & $24.35 \pm 6.99$ & $39.84 \pm 7.39$ & $41.33 \pm 6.82$ & $36.90 \pm 4.98$ & $0.090^{\mathrm{a}}$ \\
\hline Obesity $(\mathrm{BMI} \geq 30)\left[\mathrm{kg} / \mathrm{m}^{2}\right]$ & $51(43 \%)$ & $19(39 \%)$ & $30(49 \%)$ & $23.10 \pm 22.23$ & $0.167^{\mathrm{a}}$ \\
\hline Nulliparity & $48(40 \%)$ & $15(31 \%)$ & $28(46 \%)$ & $5(50 \%)$ & $0.177^{\mathrm{b}}$ \\
\hline
\end{tabular}

Data are presented as the mean \pm standard deviation (SD). ${ }^{a}$ refers to $p$-value for Kruskal-Wallis test; ${ }^{b}$ refers to $p$-value for $\chi^{2}$ test. UPA ulipristal acetate, $B M I-$ body mass index.

Table II. Serum concentrations of TNF- $\alpha$, IGF-1, and PAI-1 in studied groups

\begin{tabular}{|lccccc|}
\hline Parameter & $\begin{array}{c}\text { All subjects } \\
(N=120)\end{array}$ & $\begin{array}{c}\text { Controls } \\
(n=49)\end{array}$ & $\begin{array}{c}\text { Non-UPA } \\
(n=61)\end{array}$ & $\begin{array}{c}\text { After UPA } \\
(n=10)\end{array}$ & $\begin{array}{l}P \\
\text { TNF- } \alpha[\mathrm{pg} / \mathrm{ml}]\end{array}$ \\
\hline IGF-1 $[\mathrm{ng} / \mathrm{ml}]$ & $17.77 \pm 48.74$ & $166.06 \pm 51.63$ & $169.39 \pm 164.13$ & $202.30 \pm 61.01$ & 0.137 \\
\hline PAl-1 $[\mathrm{ng} / \mathrm{ml}]$ & $9.92 \pm 3.07$ & $10.03 \pm 3.12$ & $9.82 \pm 2.90$ & $9.91 \pm 4.11$ & 0.764 \\
\hline
\end{tabular}

Data are presented as the mean \pm standard deviation (SD), and analyzed by the Kruskal-Wallis test. TNF- $\alpha$-tumor necrosis factor alpha, IGF-1 - insulin-like growth factor 1, PAI-1 - plasminogen activator inhibitor-1.

Table III. Intergroup comparisons of TNF- $\alpha$, IGF-1, PAI-1 serum levels

\begin{tabular}{|ll|}
\hline Parameter & $P$ \\
\hline TNF- $\alpha[\mathrm{pg} / \mathrm{ml}]$ & 0.946 \\
\hline Non-UPA - after UPA & 0.0002 \\
\hline Non-UPA - Control & 0.0002 \\
\hline After UPA - Control & 0.091 \\
\hline IGF-1 [ng/ml] & 0.918 \\
\hline Non-UPA - after UPA & 0.062 \\
\hline After UPA - Control & 0.995 \\
\hline PAl-1 [ng/ml] & 0.921 \\
\hline Non-UPA - after UPA & 0.992 \\
\hline Non-UPA - Control & $109-a-t u m o r$ \\
\hline After UPA - Control & \\
\hline
\end{tabular}

Data were analyzed by post hoc Dunnett's test. TNF- $\alpha$ - tumor necrosis factor alpha, IGF-1 - insulin-like growth factor 1, PAI-1 plasminogen activator inhibitor-1.

test followed by Dunnett's multiple comparison test. The $\chi^{2}$ test was used to compare categorical data. Multivariate logistic regression analysis was performed to verify whether age and body mass index (BMI) affected serum TNF- $\alpha$ levels in subjects with UF not treated with UPA (non-UPA) and subjects without UF (controls). Due to the small size of the group of patients with UF treated with UPA, we excluded this group from the regression analysis. The value of $p<0.05$ was considered statistically significant. All analyses were performed using Statistica software (version 12.0 PL; StatSoft Inc., Tulsa, OK, USA; StatSoft, Kraków, Poland).

\section{Results}

As shown in Table I, we included a total of 120 premenopausal Polish Caucasian women, aged from 22 to 53 years. We did not find significant differences for age $(p=0.090), \mathrm{BMI}(p=0.167)$, rate of obesity ( $p=0.177)$ or nulliparity $(p=0.212)$, so these variables are not likely to have influenced study outcomes.

Values of serum TNF- $\alpha$, IGF-1, and PAI-1 concentrations in three studied groups are presented in Table II.

A statistically significant difference in TNF- $\alpha$ serum concentrations was found between the group of patients with UFs and the controls ( $p=0.00001$ ). The post hoc Dunnett's test for intergroup comparisons showed significant differences in TNF- $\alpha$ serum levels. Tumor necrosis factor alpha concentrations in the serum of patients after UPA treatment and patients without treatment were significantly higher compared to healthy controls (UPA - control, $p=0.0002$; non-UPA - control, $p=0.0002$ ). However, interestingly, there were no significant differences in TNF- $\alpha$ serum concentrations between UPA and non-UPA patients (Table III). Serum concentrations of IGF-1 and PAI-1 did not differ significantly between the groups included in the study (Table II and Table III).

Scatterplots show serum levels of TNF- $\alpha$ (Figure 1), IGF-1 (Figure 2) and PAI-1 (Figure 3) in the studied groups of patients.

Multiple regression analysis (Table IV) showed that BMI and age were important variation fac- 
Table IV. Relationship between body mass index (BMI) and tumor necrosis factor alpha (TNF- $\alpha$ ) concentration adjusted for age among patients with uterine fibroids (UFs) (non-UPA group) and control subjects without UFs

\begin{tabular}{|lcccccc|}
\hline Group & $R$ & $R^{2}$ & $F$ & $95 \% \mathrm{Cl}$ & Power of test & $P$ \\
\hline Control group & 0.415 & 0.172 & 3.124 & $0.023-0.331$ & 0.073 & 0.035 \\
\hline Non-UPA group & 0.338 & 0.114 & 2.446 & $0.006-0.245$ & 0.619 & 0.073 \\
\hline
\end{tabular}

$\mathrm{Cl}$ - confidence interval

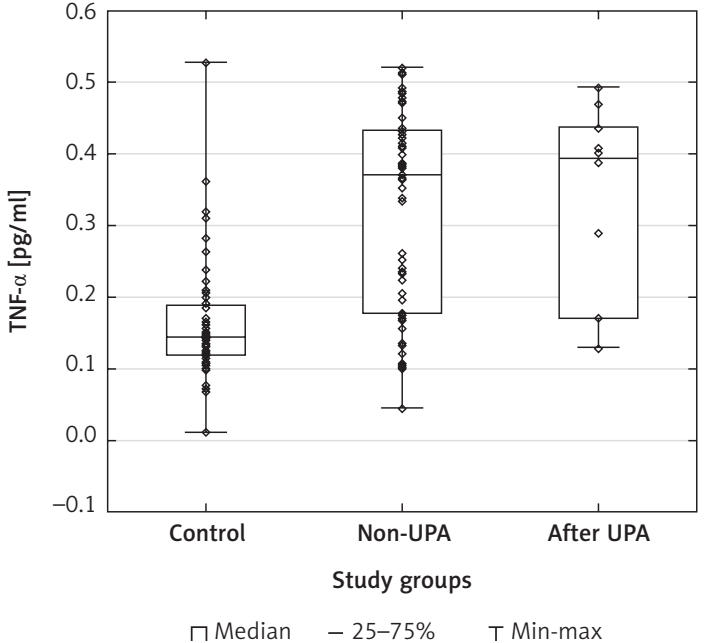

Figure 1. Scatterplot with boxplot showing tumor necrosis factor alpha (TNF- $\alpha$ ) serum concentrations in patients with uterine fibroids (after ulipristal acetate [UPA] and non-UPA) and healthy controls

tors for serum TNF- $\alpha$ concentration in the control group $(p=0.035)$. Such a correlation was not found in patients with UF (non-UPA group).

The minimum sample size of 132 is required to test whether a set of two predictor variables can predict the outcome with a minimum target value $r$-squared of 0.172 . This calculation is based on a multiple linear regression test with the values of alpha and desired power to be set at 0.05 and 0.8 respectively.

For the Kruskal-Wallis test no population parameters are estimated, so no confidence intervals are provided.

\section{Discussion}

To date, the diagnosis and management of UFs have been of paramount importance. Although a surgical approach is feasible and safe, with different minimally invasive approaches depending on the location of UFs (hysteroscopy in the case of submucosal UFs [6, 61], laparoscopy/robotic surgery for intramural/subserosal ones [62]), medical therapy is usually the first choice to reduce UF volume and related signs and symptoms.

The mechanism of the development of UFs depends on several factors, and it is still not fully understood [2, 3, 13]. For example, the influence of pregnancy on UF size still remains an unsolved

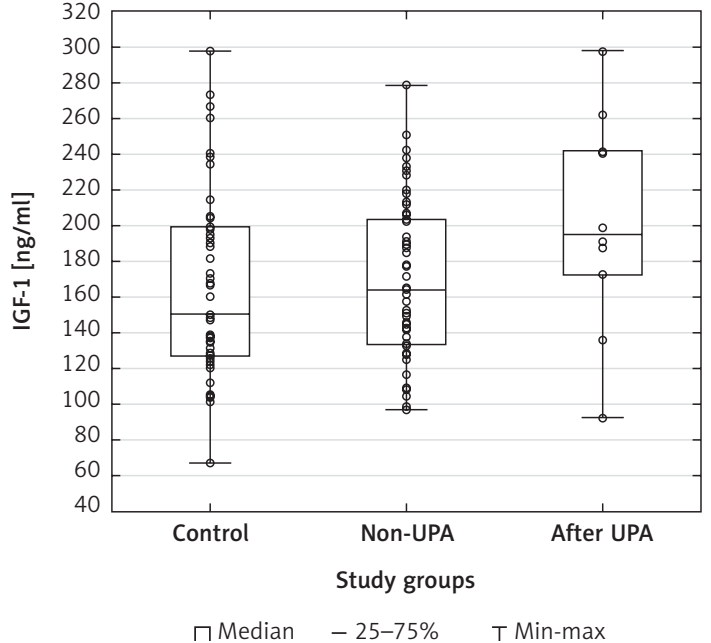

Figure 2. Scatterplot with boxplot showing insulin-like growth factor 1 (IGF-1) serum concentrations in patients with uterine fibroids (after ulipristal acetate [UPA] and non-UPA) and healthy controls

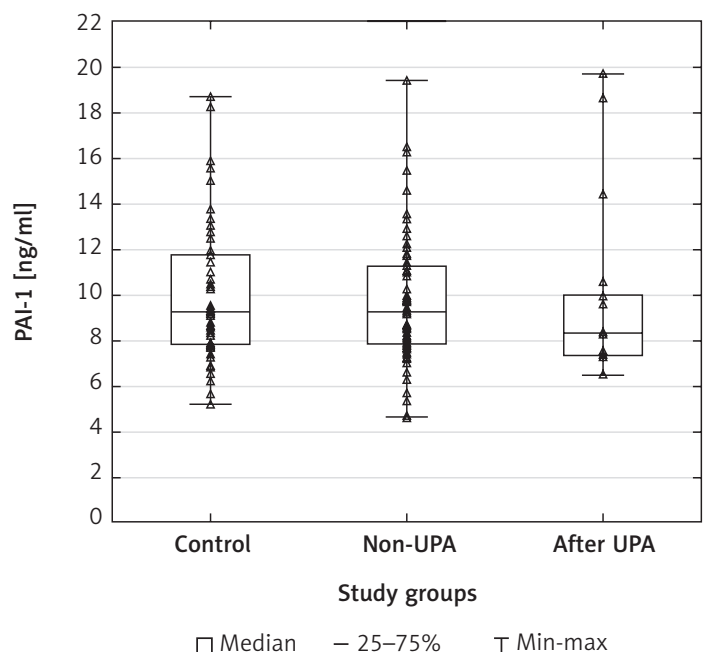

Figure 3. Scatterplot and boxplot plasminogen activator inhibitor-1 (PAI-1) serum concentrations in patients with uterine fibroids (after ulipristal acetate [UPA] and non-UPA) and healthy controls

dilemma. Based on current knowledge, physicians are not able to inform patients about the likelihood that UFs may modify their size during pregnancy [63]. According to recent data, long-term stimulation of myometrial cells by progesterone results in UF growth [16]. It is still unknown why UFs significantly increase in size during early pregnancy 
and then decrease in the third trimester $[63,64]$. Therefore, we cannot explain everything as being due to progesterone activity and we should look for other important pathways and dependencies. Some of these connections may vary depending on other hormones whose levels rise during pregnancy, e.g. glucocorticoids or prolactin.

Studies on the role of progesterone in the development of UFs were the basis for the development of pharmacological treatment with SPRMs. Additionally, SPRMs showed tissue-specific activity and partial antagonism against progesterone $[44,46,47,49,50]$. Over a few years UPA became one of the main SPRMs in the treatment of UFs and was included in the UF therapeutic scheme [52, 65, 66]. UPA is used for the preoperative treatment of moderate and severe manifestations of UFs and for the temporary treatment of moderate and severe manifestations of UFs occurring in adult women of reproductive age [67]. Despite recent reports on UPA-induced side effects such as hepatic failure, this drug is still successfully used in UF therapy. However, the occurrence of the above-mentioned complication led to the implementation of intensive monitoring of liver function throughout the treatment with UPA $[45,60,66]$. Therefore, it seems to be important to study the role of progesterone and to determine the exact mechanisms of the action of drugs (such as SPRMs) affecting the pathway of progesterone transformation in the pathophysiology of UFs [4].

In order to understand the potential causative roles in the development of UFs, the correlation between progesterone and growth factor levels has gained increasing attention $[1,20]$. Transforming growth factor beta (TGF- $\beta$ ) controls proliferation and differentiation in the majority of cell types in the human body [68] and is considered to be one of the key factors in the pathophysiology of UFs $[13,14]$. TGF- $\beta 3$ induces ECM secretion and affects its degradation $[19,69,70]$; in addition, increased concentration of TGF- $\beta 3$ in the serum was reported in patients with UFs [71, 72]. We previously found that UPA treatment may affect UFs through the TGF- $\beta 3$ pathway. In particular, levels of TGF- $\beta 3$ were comparable in the serum of patients who were treated with UPA and in the serum of patients without UFs (control group) [55].

Another dilemma is whether the location in the myometrium is in correspondence with the origin of UF and whether it plays a role in UF tumor structure and cytokine production. According to recent studies concerning progenitor cells in myometrial pathology, these cells were found to present the differential expression of cytokines related to inflammation. As found by Orciani et al. (2018), the upregulation of cytokines related to chronic inflammation may trigger the formation of a microenvironment suitable for UF formation and growth [73].

TNF- $\alpha$ is another important factor involved in UF pathophysiology [31-33], since it controls cell growth, differentiation, and apoptosis [74]. As regards tumor biology, TNF- $\alpha$ is considered as an antineoplastic and anti-angiogenic factor [31] In spite of these anticancer properties, TNF- $\alpha$ can lead to adverse effects in the course of breast tumor [75], and might also be involved in the development of UFs $[23,32]$. Abdominal and pelvic pain, infertility, and gastrointestinal manifestations may be a direct effect of tumor growth, but they may also result from its endocrine and paracrine properties associated with increased secretion of proinflammatory cytokines (e.g. TNF- $\alpha$ ). TNF- $\alpha$ is recognized as a strong aromatase stimulant, which causes enhanced conversion of androstenedione to estrone, which may intensify tumor growth [75]. In addition, it induces the expression of key genes coding for enzymes responsible for estrogen metabolism, making UF tissue more hormonally active, and intensifies the process of carcinogenesis. [76]. Interestingly, activin A, one of the main profibrotic factors, is a protein linking the TNF- $\alpha$ pathway and UFs [77]. In particular, activin $A$ was found to be capable of influencing the development of UFs mainly via the induction of ECM proteins [19, 78].

As previously found, the presence of UFs in women may lead to or be the effect of a state equivalent to non-specific systemic inflammation due to increased secretion of TNF- $\alpha$ and its higher concentrations in the serum and tissues [31, 32]. These speculations are supported by the results of the present study, in which we demonstrated significant differences between TNF- $\alpha$ concentrations in the serum of UF patients (both with and without UPA treatment) and healthy controls (UPA - control $p=0.0002$; non-UPA - control $p=0.0002$ ). We should take into account that obese patients are characterized by excessive secretion of various inflammatory mediators, in cluding TNF- $\alpha$, so obesity may have a significant impact not only on the prevalence of UFs but also on the occurrence of UF-derived symptoms [23, 79]. Nevertheless, in the present study the average BMI values were not significantly different between the analyzed groups, so this parameter is not likely to have influenced the outcomes.

Most importantly, our results did not show a significant difference in TNF- $\alpha$ concentrations between non-UPA and UPA groups ( $p=0.946$ ), suggesting that UPA does not influence TNF- $\alpha$ concentrations, in contrast to the observed reduction in TGF- $\beta 3$ after UPA therapy [55]. In our opinion, this observation may support the recommendations regarding the use of UPA in some symptoms 
associated with UFs. It was confirmed that UPA affects ECM volume, and, as a consequence, it reduces tumor volume $[53,65,80]$, excessive uterine bleeding associated with UFs [81, 82], and also abnormal bleeding occurring in patients without the diagnosis of UFs [83]. Several authors have reported that UPA reduced pelvic pain [47, 84], but the mechanism has not been fully elucidated so far. Nevertheless, in some cases the effect of UPA treatment is not fully satisfactory. It was also reported that using UPA may cause pain or discomfort within the abdomen and pelvis [85].

The precise mechanism responsible for UF-associated pain has not been fully elucidated, although stretching, compression, endocrine or paracrine actions are known factors involved. TNF- $\alpha$ stimulates the production of prostaglandins [86], and its role as a pain inducer is well documented [87, 88]. Therefore, the use of a drug with the anti-TNF- $\alpha$ component may be a solution in patients treated pharmacologically with symptomatic UFs in whom a better analgesic effect is expected, or in patients in whom such an effect was not achieved in their previous therapy. Currently, anti-TNF- $\alpha$ drugs are not used in clinical practice for UF treatment, despite the fact that a considerable part of manifestations of UFs is TNF- $\alpha$-dependent [33].

Several previous studies reported that some UFs may limit fertility or cause infertility [89]. In this scenario, UF-associated infertility may be (at least partially) due to TNF- $\alpha$ dysregulation [90]. According to available scarce evidence, women with a history of infertility have increased serum TNF- $\alpha$ concentrations in comparison with fertile controls [91]. Additionally, increased TNF- $\alpha$ levels play a detrimental role as regards the outcomes of assisted reproductive techniques [92]. In obesity, chronic inflammation and an increased TNF- $\alpha$ level may have an indirect influence on fertility [93]. Animal studies corroborated these observations and showed that using anti-TNF- $\alpha$ drugs improved reproductive outcomes [94].

Uterine fibroids treatment with UPA preserves fertility, but the use of anti-TNF- $\alpha$ together with UPA may improve the effectiveness of pharmacological therapy of infertility due to UFs. In a previous review published by our group we described compounds with confirmed anti-TNF- $\alpha$ properties, i.e. pentoxifylline, capsaicin and non-steroidal anti-inflammatory drugs (NSAIDs) [32]. In our opinion, a combination therapy with UPA and one of these substances may improve the fertility of patients with UFs due to the effect on TNF- $\alpha$ levels [65], although this hypothesis needs to be verified in large human trials.

To date, available data have indicated that both IGF-1 [34, 35] and PAI-1 [40] may be important in the pathophysiology of UFs and the treatment of UFs may influence their serum concentrations. Asoprisnil, a type of SPRM, was found to reduce the expression of IGF-1 and its receptor in UF cells [95]. Nevertheless, our results did not show a significant difference of IGF-1 and PAI-1 levels in the serum between UF patients and the controls, and between UPA-treated UF patients and non-UPA patients. Interestingly, a previous study demonstrated reduced expression of TGF- $\beta 3$ in UF cells cultured with asoprisnil [95]. Similarly, data analysis in our previous study showed that UPA treatment is associated with lowered TGF- $\beta 3$ concentrations in the serum and in UF tissue [55]. Therefore, additional research is necessary to assess the influence of drugs on growth factors in patients with UFs.

What are our recommendations as regards the interpretation of the above results? The identification of all signal transduction pathways in UFs will be impossible for a long time because of the abundance of their components. To date, the significance of TGF- $\beta[14,96]$, TNF- $\alpha$ [33], or, according to recent data, neurogenic growth factors [97] seems to have been confirmed in the pathophysiology of UFs. Researchers are still studying whether other growth factors, cytokines and chemokines may be similarly significant. In our viewpoint the above results indicate that IGF-1 and PAI-1 are of secondary importance compared to the above-mentioned factors. Obviously, further studies are necessary in this area.

One of the main steps to take in the treatment of UFs will be patient-tailored treatment. An increasing proportion of patients decline surgical treatment in favor of pharmacotherapy regimens. This lead should be partially followed to offer the patients effective treatment with medications only. In our viewpoint subsequent studies should focus on analyzing which factors play a specific role in the formation and growth of UFs, which drugs have an effect on specific factors, and how to combine the drugs effectively to provide the appropriate clinical effect. Currently, it seems exceptionally difficult, but more effort will make it possible to reach the target. The present study fits this purpose.

Knowledge concerning the effect of drugs depending on the dose and types of drug combinations will be a good starting point to analyze synergisms. A relatively high price and often difficult accessibility are the main disadvantages of available drugs registered in UF treatment. None of the available drugs may be used for prevention of the development of these tumors [52]. Until now, no hormonally active agents have been qualified for long-term treatment of UFs because of associated side effects $[60,66]$. Co-drugs that present differ- 
ent kinds of synergy may be a potential paradigm shift for future anti-UF therapy and, in our opinion, these pathways deserve to be extensively explored. For example, a recent study found a reduction in the growth of UFs in vitro due to the synergistic effect of UPA and vitamin D [98]. Another synergism, which is less commonly known, but seems to be important in the treatment with UPA, is its combination with simvastatin [99]. Therefore, we take the opportunity to solicit future investigation for new combinations of drugs effective in the treatment of UFs and their symptoms.

The main advantage of the present study is new knowledge concerning growth factors in the pathophysiology of UFs. Another important issue is the fact that the study presents the effect of the anti-UF drug UPA on growth factors. Detailed data regarding the effect of this drug on pathophysiological pathways in UFs are still hardly available and each piece of information is important, especially after some research was suspended following the alert issued by the European Medicines Agency [58]. This study bridges such gaps and offers new knowledge about IGF-1 and PAI-1 factors. Moreover, it partially complements data concerning TNF- $\alpha$. The main limitation of this study results from a relatively small sample size, especially in the group of patients treated with UPA. Conducting research on this drug is challenging in Poland due to the low popularity of the drug and the fact that physicians tend to choose surgical methods in the treatment rather than pharmacotherapy.

In conclusion, uterine fibroids occur in a large number of women and are a considerable problem of health care systems worldwide. Therefore, extensive research should be conducted to find new treatment methods and to optimize already existing therapies. No significant differences were found between TNF- $\alpha$ concentrations in the serum of patients with UFs treated with UPA, and patients without UPA treatment. In addition, our data analysis did not show significant differences in the concentrations of IGF-1 and PAI-1 between patients with UFs and the control group.

Personalized therapies using symptom-specific drugs or co-drugs should be a new direction in anti-UF research. However, according to the available data, further extensive research is mandatory. Future studies on this topic should also take into account that UFs might cause a different effect on cytokines and growth factors in relation to various localization and origin of lesions.

\section{Acknowledgments}

This study was funded by the Center of Postgraduate Medical Education, grant number 501 1-21-27-16, 501-1-21-27-17 and 501-1-21-27-18. The laboratory part of this study was carried out using CePT infrastructure financed by the European Union - the European Regional Development Fund within the Operational Program (Innovative Economy for 2007-2013).

\section{Conflict of interest}

The authors declare no conflict of interest.

\section{References}

1. Lagana AS, Vergara D, Favilli A, et al. Epigenetic and genetic landscape of uterine leiomyomas: a current view over a common gynecological disease. Arch Gynecol Obstet 2017; 296: 855-67.

2. Parker WH. Etiology, symptomatology, and diagnosis of uterine myomas. Fertil Steril 2007; 87: 725-36.

3. Stewart EA, Laughlin-Tommaso SK, Catherino WH, Lalitkumar S, Gupta D, Vollenhoven B. Uterine fibroids. Nat Rev Dis Primers 2016; 2: 16043.

4. Al-Hendy A, Myers ER, Stewart E. Uterine fibroids: burden and unmet medical need. Semin Reprod Med 2017; 35: 473-80.

5. Herve F, Katty A, Isabelle Q, Celine S. Impact of uterine fibroids on quality of life: a national cross-sectional survey. Eur J Obstet Gynecol Reprod Biol 2018; 229: 32-7.

6. Lagana AS, Alonso Pacheco L, Tinelli A, et al. Management of asymptomatic submucous myomas in women of reproductive age: a consensus statement from the Global Congress on Hysteroscopy Scientific Committee. J Minim Invasive Gynecol 2019; 26: 381-3.

7. Zepiridis LI, Grimbizis GF, Tarlatzis BC. Infertility and uterine fibroids. Best Pract Res Clin Obstet Gynaecol 2016; 34: 66-73.

8. Parazzini F, Tozzi L, Bianchi S. Pregnancy outcome and uterine fibroids. Best Pract Res Clin Obstet Gynaecol 2016; 34: 74-84.

9. Vitagliano A, Noventa M, Di Spiezio Sardo A, et al. Uterine fibroid size modifications during pregnancy and puerperium: evidence from the first systematic review of literature. Arch Gynecol Obstet 2018; 297: 823-35.

10. Munro MG, Critchley HO, Broder MS, Fraser IS, Disorders FWGoM. FIGO classification system (PALM-COEIN) for causes of abnormal uterine bleeding in nongravid women of reproductive age. Int J Gynaecol Obstet 2011; 113: 3-13.

11. Wozniak A, Wozniak S. Ultrasonography of uterine leiomyomas. Prz Menopauzalny 2017; 16: 113-7.

12. Soliman AM, Yang H, Du EX, Kelkar SS, Winkel C. The direct and indirect costs of uterine fibroid tumors: a systematic review of the literature between 2000 and 2013. Am J Obstet Gynecol 2015; 213: 141-60.

13. Bulun SE. Uterine fibroids. N Engl J Med 2013; 369: 1344-55.

14. Ciebiera M, Wlodarczyk M, Wrzosek $M$, et al. Role of transforming growth factor beta in uterine fibroid biology. Int J Mol Sci 2017; 18: 2435.

15. Yang Q, Mas A, Diamond MP, Al-Hendy A. The mechanism and function of epigenetics in uterine leiomyoma development. Reprod Sci 2016; 23: 163-75.

16. Ishikawa H, Ishi K, Serna VA, Kakazu R, Bulun SE, Kurita T. Progesterone is essential for maintenance and growth of uterine leiomyoma. Endocrinology 2010; 151: 2433-42.

17. Chill HH, Safrai M, Reuveni Salzman A, Shushan A. The rising phoenix-progesterone as the main target of the medical therapy for leiomyoma. Biomed Res Int 2017; 2017: 4705164. 
18. Makinen N, Mehine M, Tolvanen J, et al. MED12, the me diator complex subunit 12 gene, is mutated at high frequency in uterine leiomyomas. Science 2011; 334: 252-5

19. Islam MS, Ciavattini A, Petraglia F, Castellucci M, Ciarmela P. Extracellular matrix in uterine leiomyoma pathogenesis: a potential target for future therapeutics. Hum Reprod Update 2018; 24: 59-85.

20. Ciarmela P, Islam MS, Reis FM, et al. Growth factors and myometrium: biological effects in uterine fibroid and possible clinical implications. Hum Reprod Update 2011; 17: 772-90.

21. Dixon D, He H, Haseman JK. Immunohistochemical localization of growth factors and their receptors in uterine leiomyomas and matched myometrium. Environ Health Perspect 2000; 108 Suppl 5: 795-802.

22. Maruo T, Ohara N, Wang J, Matsuo H. Sex steroidal regulation of uterine leiomyoma growth and apoptosis. Hum Reprod Update 2004; 10: 207-20.

23. Protic O, Toti P, Islam MS, et al. Possible involvement of inflammatory/reparative processes in the development of uterine fibroids. Cell Tissue Res 2016; 364: 415-27.

24. Kurachi O, Matsuo H, Samoto T, Maruo T. Tumor necrosis factor-alpha expression in human uterine leiomyoma and its down-regulation by progesterone. J Clin Endocrinol Metab 2001; 86: 2275-80.

25. Locksley RM, Killeen N, Lenardo MJ. The TNF and TNF receptor superfamilies: integrating mammalian biology. Cell 2001; 104: 487-501.

26. Islam MS, Protic O, Stortoni P, et al. Complex networks of multiple factors in the pathogenesis of uterine leiomyoma. Fertil Steril 2013; 100: 178-93.

27. Ghomari-Boukhatem H, Bouchouicha A, Mekki K, Chenni K, Belhadj M, Bouchenak M. Blood pressure, dyslip idemia and inflammatory factors are related to body mass index in scholar adolescents. Arch Med Sci 2017; 13: 46-52

28. Moghtadaei M, Otoukesh B, Pazoki-Toroudi H, Boddouhi B, Yeganeh A. Evaluation of inflammatory response in patients undergoing surgical treatment for early and delayed femoral fractures. Arch Med Sci 2019; 15: 141-5.

29. Nair S, Al-Hendy A. Adipocytes enhance the prolifera tion of human leiomyoma cells via TNF-alpha proinflammatory cytokine. Reprod Sci 2011; 18: 1186-92.

30. Plewka A, Madej P, Plewka D, et al. Immunohistochemical localization of selected pro-inflammatory factors in uterine myomas and myometrium in women of various ages. Folia Histochem Cytobiol 2013; 51: 73-83.

31. Wolanska M, Taudul E, Bankowska-Guszczyn E, Kinalski M. Tumor necrosis factor in uterine leiomyomas at various stages of tumor growth. Ginekol Pol 2010; 81: 431-4.

32. Ciebiera M, Wlodarczyk M, Wrzosek $M$, et al. TNF-alpha serum levels are elevated in women with clinically symptomatic uterine fibroids. Int J Immunopathol Pharmacol 2018; 32: 2058738418779461.

33. Ciebiera M, Wlodarczyk M, Zgliczynska M, et al. The role of tumor necrosis factor alpha in the biology of uterine fibroids and the related symptoms. Int J Mol Sci 2018 19; doi: 10.3390/ijms19123869.

34. Brahmkhatri VP, Prasanna C, Atreya HS. Insulin-like growth factor system in cancer: novel targeted therapies. Biomed Res Int 2015; 2015: 538019.

35. Giudice LC, Irwin JC, Dsupin BA, et al. Insulin-like growth factor (IGF), IGF binding protein (IGFBP), and IGF receptor gene expression and IGFBP synthesis in human uterine leiomyomata. Hum Reprod 1993; 8: 1796-806.

36. Peng L, Wen Y, Han Y, et al. Expression of insulin-like growth factors (IGFs) and IGF signaling: molecular com- plexity in uterine leiomyomas. Fertil Steril 2009; 91: 2664-75.

37. Di X, Yu L, Moore AB, et al. A low concentration of genistein induces estrogen receptor-alpha and insulinlike growth factor-I receptor interactions and proliferation in uterine leiomyoma cells. Hum Reprod 2008; 23: 1873-83.

38. Soloff MS, Jeng YJ, Izban MG, et al. Effects of progesterone treatment on expression of genes involved in uterine quiescence. Reprod Sci 2011; 18: 781-97.

39. Vaughan DE. PAI-1 and atherothrombosis. J Thromb Haemost 2005; 3: 1879-83.

40. Durand MK, Bodker JS, Christensen A, et al. Plasminogen activator inhibitor-I and tumour growth, invasion, and metastasis. Thromb Haemost 2004; 91: 438-49.

41. Poredos P, Spirkoska A, Jezovnik MK. In patients with superficial vein thrombosis the inflammatory response is increased and related to the recanalization rate. Arch Med Sci 2019; 15: 393-401.

42. Sourla A, Polychronakos C, Zeng WR, et al. Plasminogen activator inhibitor 1 messenger RNA expression and molecular evidence for del(7)(q22) in uterine leiomyomas. Cancer Res 1996; 56: 3123-8.

43. Rutanen E, Hurskainen R, Finne P, Nokelainen K. Induction of endometrial plasminogen activator-inhibitor 1 : a possible mechanism contributing to the effect of intrauterine levonorgestrel in the treatment of menorrhagia. Fertil Steril 2000; 73: 1020-4.

44. Donnez J, Donnez O, Courtoy GE, Dolmans MM. The place of selective progesterone receptor modulators in myoma therapy. Minerva Ginecol 2016; 68: 313-20.

45. Donnez J, Arriagada P, Donnez O, Dolmans MM. Emerging treatment options for uterine fibroids. Expert Opin Emerg Drugs 2018; 23: 17-23.

46. Chabbert-Buffet N, Meduri G, Bouchard P, Spitz IM. Selective progesterone receptor modulators and progesterone antagonists: mechanisms of action and clinical applications. Hum Reprod Update 2005; 11: 293-307.

47. Donnez J, Tatarchuk TF, Bouchard P, et al. Ulipristal acetate versus placebo for fibroid treatment before surgery. N Engl J Med 2012; 366: 409-20.

48. Donnez J, Tomaszewski J, Vazquez F, et al. Ulipristal acetate versus leuprolide acetate for uterine fibroids. N Engl J Med 2012; 366: 421-32.

49. Donnez J, Vazquez F, Tomaszewski J, et al. Long-term treatment of uterine fibroids with ulipristal acetate. Fertil Steril 2014; 101: 1565-73.e1-18.

50. Ali M, Chaudhry ZT, Al-Hendy A. Successes and failures of uterine leiomyoma drug discovery. Expert Opin Drug Discov 2018; 13: 169-77.

51. Simon JA, Catherino W, Segars JH, et al. Ulipristal acetate for treatment of symptomatic uterine leiomyomas: a randomized controlled trial. Obstet Gynecol 2018; 131: 431-9.

52. Faustino F, Martinho M, Reis J, Aguas F. Update on medical treatment of uterine fibroids. Eur J Obstet Gynecol Reprod Biol 2017; 216: 61-8.

53. Courtoy GE, Henriet P, Marbaix E, et al. Matrix metalloproteinase activity correlates with uterine myoma volume reduction after ulipristal acetate treatment. J Clin Endocrinol Metab 2018; 103: 1566-73.

54. Courtoy GE, Donnez J, Marbaix E, Dolmans MM. In vivo mechanisms of uterine myoma volume reduction with ulipristal acetate treatment. Fertil Steril 2015; 104: 42634.e1.

55. Ciebiera M, Wlodarczyk M, Wrzosek M, SlabuszewskaJozwiak A, Nowicka G, Jakiel G. Ulipristal acetate de- 
creases transforming growth factor beta3 serum and tumor tissue concentrations in patients with uterine fibroids. Fertil Steril 2018; 109: 501-7.e2.

56. Small B, Millard CEF, Kisanga EP, et al. The selective progesterone receptor modulator ulipristal acetate inhibits the activity of the glucocorticoid receptor. J Clin Endocrinol Metab 2020; 105. doi: 10.1210/clinem/dgz139.

57. Agha A, Monson JP. Modulation of glucocorticoid metabolism by the growth hormone - IGF-1 axis. Clin Endocrinol (Oxf) 2007; 66: 459-65.

58. Ulipristal acetate (Esmya): restrictions on use. Drug Ther Bull 2018; 56: 127.

59. Donnez J. Liver injury and ulipristal acetate: an overstated tragedy? Fertil Steril 2018; 110: 593-5.

60. Donnez J, Arriagada P, Marciniak M, Larrey D. Liver safety parameters of ulipristal acetate for the treatment of uterine fibroids: a comprehensive review of the clinical development program. Expert Opin Drug Saf 2018; 17: 1225-32.

61. Vitale SG, Sapia F, Rapisarda AMC, et al. Hysteroscopic morcellation of submucous myomas: a systematic review. Biomed Res Int 2017; 2017: 6848250.

62. Flyckt R, Coyne K, Falcone T. Minimally invasive myomectomy. Clin Obstet Gynecol 2017; 60: 252-72.

63. Vitale SG, Padula F, Gulino FA. Management of uterine fibroids in pregnancy: recent trends. Curr Opin Obstet Gynecol 2015; 27: 432-7.

64. De Vivo A, Mancuso A, Giacobbe A, et al. Uterine myomas during pregnancy: a longitudinal sonographic study. Ultrasound Obstet Gynecol 2011; 37: 361-5.

65. Ali M, Al-Hendy A. Selective progesterone receptor modulators for fertility preservation in women with symptomatic uterine fibroids. Biol Reprod 2017; 97: 337-52.

66. Donnez J, Courtoy GE, Dolmans MM. Fibroid management in premenopausal women. Climacteric 2019; 22 27-33

67. European Medicine Agency. Esmya 2019. Available from: https://www.ema.europa.eu/en/medicines/human/ referrals/esmya (Accessed: 28.11.2019).

68. Horiguchi M, Ota M, Rifkin DB. Matrix control of transforming growth factor-beta function. J Biochem 2012; 152: 321-9.

69. Norian JM, Malik M, Parker CY, et al. Transforming growth factor beta3 regulates the versican variants in the extracellular matrix-rich uterine leiomyomas. Reprod Sci 2009; 16: 1153-64.

70. Halder SK, Goodwin JS, Al-Hendy A. 1,25-Dihydroxyvitamin D3 reduces TGF-beta3-induced fibrosis-related gene expression in human uterine leiomyoma cells. J Clin Endocrinol Metab 2011; 96: E754-62.

71. Ciebiera M, Wlodarczyk M, Slabuszewska-Jozwiak A, Nowicka G, Jakiel G. Influence of vitamin D and transforming growth factor beta3 serum concentrations, obesity, and family history on the risk for uterine fibroids. Fertil Steril 2016; 106: 1787-92.

72. Halder S, Al-Hendy A. Hypovitaminosis D and high serum transforming growth factor beta-3: important biomarkers for uterine fibroids risk. Fertil Steril 2016; 106: 1648-9.

73. Orciani M, Caffarini M, Biagini A, et al. Chronic inflammation may enhance leiomyoma development by the involvement of progenitor cells. Stem Cells Int 2018; 2018: 1716246

74. Bradley JR. TNF-mediated inflammatory disease. J Patho 2008; 214: 149-60.

75. Macdiarmid F, Wang D, Duncan LJ, Purohit A, Ghilchick MW, Reed MJ. Stimulation of aromatase activity in breast fi- broblasts by tumor necrosis factor alpha. Mol Cell Endocrinol 1994; 106: 17-21.

76. Kamel M, Shouman S, El-Merzebany M, et al. Effect of tumour necrosis factor-alpha on estrogen metabolic pathways in breast cancer cells. J Cancer 2012; 3: 310-21.

77. Protic O, Islam MS, Greco S, et al. Activin A in inflammation, tissue repair, and fibrosis: possible role as inflammatory and fibrotic mediator of uterine fibroid development and growth. Semin Reprod Med 2017; 35: 499-509.

78. Bao H, Sin TK, Zhang G. Activin A induces leiomyoma cell proliferation, extracellular matrix (ECM) accumulation and myofibroblastic transformation of myometrial cells via p38 MAPK. Biochem Biophys Res Commun 2018; 504: 447-53.

79. Ellulu MS, Patimah I, Khaza'ai H, Rahmat A, Abed Y. Obesity and inflammation: the linking mechanism and the complications. Arch Med Sci 2017; 13: 851-63.

80. Baggio S, Pomini P, Galeone F, et al. Influence of ulipristal acetate therapy on uterine fibroid-related symptoms and on uterine and fibroid volumes and vascularity in dices assessed by ultrasound. J Ultrasound Med 2018; 37: 2215-23.

81. Gracia M, Alcala M, Ferreri J, et al. Ulipristal acetate improves clinical symptoms in women with adenomyosis and uterine myomas. J Minim Invasive Gynecol 2018; 25: $1274-80$.

82. Bouchard P, Chabbert-Buffet N. The history and use of the progesterone receptor modulator ulipristal acetate for heavy menstrual bleeding with uterine fibroids. Best Pract Res Clin Obstet Gynaecol 2017; 40: 105-10.

83. Estadella J, Espanol P, Ascencio F, Perello J, Calaf J. Ulipristal acetate for the management of acute heavy menstrual bleeding without fibroids. Gynecol Endocrinol 2018; 34: 554-7.

84. Brun JL, Rajaonarison J, Froeliger A, Monseau-Thiburce AC, Randriamboavonjy R, Vogler A. Outcome of patients with uterine fibroids after 3-month ulipristal acetate therapy. Eur J Obstet Gynecol Reprod Biol 2018; 222: 13-8.

85. Hong YH, Han SJ, Lee D, Kim SK, Jee BC. Adverse symptoms during short-term use of ulipristal acetate in women with uterine myomas and/or adenomyosis. J Obstet Gynaecol Res 2019; 45: 865-70.

86. Chen DB, Yang ZM, Hilsenrath R, Le SP, Harper MJ. Stimulation of prostaglandin (PG) F2 alpha and PGE2 release by tumour necrosis factor-alpha and interleukin-1 alpha in cultured human luteal phase endometrial cells. Hum Reprod 1995; 10: 2773-80.

87. Sommer C, Kress M. Recent findings on how proinflammatory cytokines cause pain: peripheral mechanisms in inflammatory and neuropathic hyperalgesia. Neurosc Lett 2004; 361: 184-7.

88. Dogru HY, Ozsoy AZ, Karakus N, Delibas IB, Isguder CK, Yigit S. Association of genetic polymorphisms in TNF and MIF gene with the risk of primary dysmenorrhea. Biochem Genet 2016; 54: 457-66.

89. Pritts EA, Parker WH, Olive DL. Fibroids and infertility: an updated systematic review of the evidence. Fertil Steri 2009; 91: 1215-23.

90. Iwabe T, Harada T, Terakawa N. Role of cytokines in endometriosis-associated infertility. Gynecol Obstet Invest 2002; 53 Suppl 1: 19-25.

91. Wang C, Ng S, Kwak-Kim J, Gilman-Sachs A, Beer A, Beaman K. Increased tumor necrosis factor-alpha level in infertility patient. Clin Appl Immunol Rev 2002; 3: 6.

92. Falconer H, Sundqvist J, Gemzell-Danielsson K, von Schoultz B, D'Hooghe TM, Fried G. IVF outcome in wom- 
en with endometriosis in relation to tumour necrosis factor and anti-Mullerian hormone. Reprod Biomed Online 2009; 18: 582-8.

93. Orostica L, Astorga I, Plaza-Parrochia F, et al. Proinflammatory environment and role of TNF-alpha in endometrial function of obese women having polycystic ovarian syndrome. Int J Obes (Lond) 2016; 40: 1715-22.

94. Naylor AJ, Desanti G, Saghir AN, Hardy RS. TNFalpha depleting therapy improves fertility and animal welfare in TNFalpha-driven transgenic models of polyarthritis when administered in their routine breeding. Lab Anim 2018; 52: 59-68.

95. Wang J, Ohara N, Wang Z, et al. A novel selective proges terone receptor modulator asoprisnil (J867) down-regulates the expression of EGF, IGF-I, TGFbeta3 and their receptors in cultured uterine leiomyoma cells. Hum Reprod 2006; 21: 1869-77.

96. Lewis TD, Malik M, Britten J, Parikh T, Cox J, Catherino WH. Ulipristal acetate decreases active TGF-beta3 and its canonical signaling in uterine leiomyoma via two novel mechanisms. Fertil Steril 2019; 111: 806-15.e1.

97. Luddi A, Marrocco C, Governini L, et al. Increased expression of neurogenic factors in uterine fibroids. Hum Reprod 2019; 34: 2153-62.

98. Ali M, Shahin SM, Sabri NA, Al-Hendy A, Yang Q. 1,25Dihydroxyvitamin D3 enhances the antifibroid effects of ulipristal acetate in human uterine fibroids. Reprod Sci 2019; 26: 812-28.

99. Malik MC, Laknaur A, Ali M, Al-Hendy A, Segars J, Borahay $M$. Synergistic effects of simvastatin and ulipristal acetate on uterine leiomyoma. Fertil Steril 2017; 108: e65. 